Yasutsugu Chinen · Takaya Tohma

Yoshinori Izumikawa · Hiroyuki Uehara

Takao Ohta

\title{
Sanfilippo type B syndrome: five patients with an R565P homozygous mutation in the $\alpha$ - $N$-acetylglucosaminidase gene from the Okinawa islands in Japan
}

Received: 9 February 2005/ Accepted: 25 April 2005/Published online: 3 June 2005

(C) The Japan Society of Human Genetics and Springer-Verlag 2005

\begin{abstract}
Sanfilippo type B syndrome (mucopolysaccharidosis type IIIB; MPS IIIB) is an autosomal recessive lysosomal storage disorder that is caused by defective $\alpha$ - $N$-acetylglucosaminidase (NAGLU). We performed NAGLU gene analysis in five patients with MPS IIIB whose respective parents from the Okinawa islands in Japan were not apparently consanguineous. We found a missense mutation (R565P) in all five patients (all homozygotes). We screened this mutation in 200 healthy subjects and found one heterozygote (none of the subjects were related to the patients). These results suggest that there may be a founder effect that results in the accumulation of R565P mutation in this area.
\end{abstract}

Keywords Sanfilippo type B syndrome ·

Mucopolysaccharidosis type IIIB ·

$\alpha$ - $N$-acetylglucosaminidase (NAGLU) .

Founder effect

\section{Introduction}

Sanfilippo type B syndrome (mucopolysaccharidosis type IIIB; MPS IIIB) is an autosomal recessive lysosomal storage disorder that is caused by defective $\alpha-N$ acetylglucosaminidase (NAGLU). This defect in NAGLU, which plays a role in the catabolism of heparan sulfate, leads to the accumulation of this substrate in lysosomes. The MPS IIIB is characterized by progressive neurodegeneration, intractable behavior problems, mild skeletal changes, and a short lifespan. The clinical severity of MPS IIIB ranges from mild to severe.

Y. Chinen $(\varangle) \cdot$ T. Tohma $\cdot$ Y. Izumikawa $\cdot$ H. Uehara $\cdot$ T. Ohta Department of Pediatrics, Faculty of Medicine, University of the Ryukyus, 207 Uehara, Nishihara, Okinawa, 903-0125 Japan

E-mail: ychinen@med.u-ryukyu.ac.jp

Tel.: + 81-98-8951154

Fax: $+81-98-8951418$
The human NAGLU gene (GenBank Accession No. U43572) is located on chromosome 17q21.1 and contains six exons coding for 743 amino acids (Weber et al. 1996; Zhao et al. 1996). Tanaka et al. (2002) reported three MPS IIIB patients in two families from the Okinawa islands with an R565P mutation. We analyzed the NAGLU gene in five patients with severe clinical profiles, excluding the above three patients.

\section{Subjects and methods}

Clinical presentation of patient and control groups

The various phenotypes in our six MPS IIIB patients are shown in Table 1. Their respective parents were apparently not related. These five patients were diagnosed based on dysmorphic faces, neurological evaluation, skeletal anomalies, and elevated urinary excretion of heparan sulfate. The NAGLU activities in fibroblasts were assayed by the method of Hall et al. (1978). In three patients (P3, P4, and P5), NAGLU activities in fibroblasts were less than $2 \%$ of those in the normal control. The NAGLU activities were not assayed in the other two patients (P1 and P2) because of their parents' refusal. As shown in Table 1, P1, P2, and P4 showed a typical, severe, clinical phenotype with impaired gait and language comprehension since 12 years of age. P4 had heart defects of mitral and aortic insufficiency. P3 could walk by herself before she died unexpectedly at 15 years of age. P5 had particularly prominent skeletal anomalies at 3 years of age. Brain MRI revealed hypoplasia of the cerebellum, megacisterna magna, brain atrophy, ventricular enlargement, and Dandy-Walker complex. P2 and P3 were deaf, and P1 and P3 had epilepsy (Table 1). Control subjects (200 unaffected and unrelated individuals) consisted of students and volunteers from the staff of the Faculty of Medicine, University of the Ryukyus. 
Table 1 Summary of clinical phenotype in five patients. $N$ not assayed, n.i. not identified

\begin{tabular}{|c|c|c|c|c|c|c|c|c|c|}
\hline $\begin{array}{l}\text { Patient } \\
\text { number }\end{array}$ & $\begin{array}{l}\text { Age of } \\
\text { observation } \\
\text { (years) }\end{array}$ & $\begin{array}{l}\text { Age of } \\
\text { diagnosis } \\
\text { (years) }\end{array}$ & $\begin{array}{l}\text { NAGLU } \\
\text { activity } \\
(\% \text { control) }\end{array}$ & $\begin{array}{l}\text { Dysmorphic } \\
\text { faces }\end{array}$ & Dysostosis & Deafness & Epilepsy & $\begin{array}{l}\text { Mental } \\
\text { retardation }\end{array}$ & Phenotype \\
\hline $\mathrm{P} 2$ & 21 & 2 & $\mathrm{~N}$ & + & + & + & - & ++ & Severe \\
\hline P3 & 15 & 4.7 & n.i. & + & + & + & + & ++ & Severe \\
\hline P4 & 15 & 4 & 1.2 & ++ & + & - & - & ++ & Severe \\
\hline
\end{tabular}

Polymerase chain reaction (PCR) and sequencing

Genomic DNA was purified from white blood cells, and genomic DNA was amplified in vitro by PCR. Multiple pairs of primers were synthesized to amplify each of the NAGLU exonic regions, including intron/exon boundaries, referring to the method of Zhao et al. (1998). Direct sequencing of DNA fragments of exons 1-6 was performed with an ABI PRISM Bigdye Terminator Cycle Sequencing Ready Reaction Kit (PE Applied Biosystems) and an ABI model 310 autosequencer.

SacII analysis of patients and volunteers

for the detection of R565P mutation

The region flanking the mutation was amplified by PCR using genomic DNAs. The antisense engineered primer '5'-GCTGACCAGCTCCTGCACTGCCCGC' was synthesized to amplify a restriction site created using the sense primer ' 5 '-CTCCGGAGTGTGTACAACTGCTCCG'. This created a substitution of A to $G$, and a mutation of $\mathrm{G}$ to $\mathrm{C}(\mathrm{R} 565 \mathrm{P})$ resulted in the generation of a $\mathrm{SacII}$ site in a mutant allele.

\section{Results}

The resulting PCR products of the NAGLU gene from all five patients were analyzed by direct sequencing. The

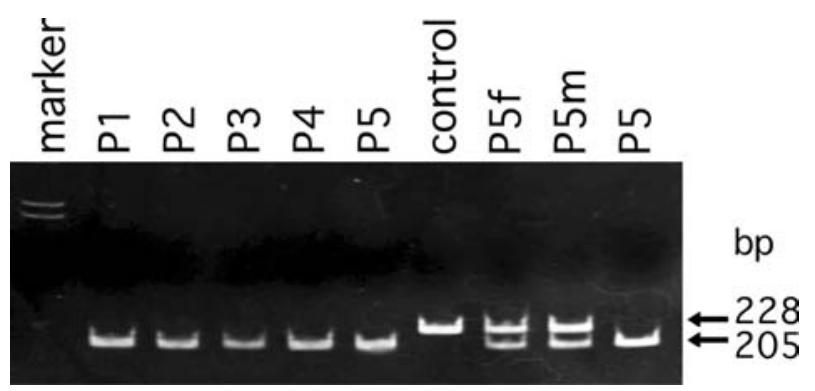

Fig. 1 Gene tracking of an R565P mutation of the NAGLU gene in five patients (P1-5) and both parents of P5 (P5f: the father of P5, $P 5 \mathrm{~m}$ : the mother of $\mathrm{P} 5$ ). As PCR products with a substitution of $\mathrm{G}$ to $\mathrm{C}(\mathrm{R} 565 \mathrm{P})$ using the engineering primers creates a $\mathrm{SacII}$ site, $228 \mathrm{bp}$ of PCR products with the mutation are digested to a $205 \mathrm{bp}$ fragment by SacII. All five patients were homozygous for R565P while both parents of P5 were heterozygous nucleotide positions are numbered according to GenBank database entry U43572. One point mutation was identified in the region of exon 6 at a nucleotide position 8839. This substitution of $\mathrm{G}$ to $\mathrm{C}$, encoding amino acid 565 , leads to an amino acid change from arginine to proline (R565P). Sequencing analysis of the R565P mutation showed that all five patients were homozygous. One polymorphism was found in the noncoding region, including g2739G $\rightarrow \mathrm{C}$ (intron $2 ; 10 / 10$ alleles). Other polymorphisms, such as g1352insC, a2259A $\rightarrow \mathrm{C}$, and g2304insA (Tanaka et al. 2002), were not analyzed. To confirm the homozygous R565P mutation, SacII digestion of PCR products was performed using the engineered primers from five patients and both of the parents of P5. The digested PCR products were analyzed by electrophoresis on $4 \%$ acrylamide gels. The DNA size of undigested normal alleles was $228 \mathrm{bp}$ while digested mutant alleles measured $205 \mathrm{bp}$. Both alleles from the five patients and one allele from each parent of P5 were digested (Fig. 1), which revealed that all five patients were homozygous for R565P while both parents of P5 were heterozygous. To detect an R565P mutation in the 200 control subjects, SacII analysis was performed using the above primers: one person was heterozygous for R565P.

\section{Discussion}

In the present study, we identified an R565P homozygous mutation in five MPS IIIB patients in five unrelated families. Although the NAGLU activities in fibroblasts from P1 and P2 were not assayed, both patients had a typically severe clinical course as MPS III and a R565P homozygous mutation of the NAGLU gene. To date, one MPS IIIB patient with a severe clinical phenotype who was compound heterozygous for R565P/delTG1035 has been reported from Australia (Weber et al. 1999). Since little is known about the catalytic site and tertiary structure of the enzyme, it is very difficult to draw any conclusions on the effect of the missense mutation on enzyme function. However, two other missense mutations at Arg-565 (R565W and R565Q) have been reported in MPS IIIB patients with a severe phenotype (Beesley et al. 1998; Bunge et al. 1999; Weber et al. 1999; Tanaka et al. 2002). Arginine is positively charged and more hydrophilic than proline, which is uncharged and moderately polar (Nelson and Cox 2000). A proline 
residue reduces the structural flexibility of a polypeptide. Thus, it seems reasonable to consider that the amino acid substitution of proline for Arg-565 may alter the charge of the polypeptide and may affect the stability and catalytic function of the NAGLU enzyme. Furthermore, Arg-565 in human NAGLU is conserved in other species, including the mouse, emu, and Arabidopsis thaliana (GenBank Accession Nos. U43573, NM 013792, AF331668, and NM 121372). These findings taken together suggest that mutations at R565P may be responsible for the defect in NAGLU in our patients with MPS IIIB. Since the Arg-565 codon (CGG) includes $\mathrm{CpG}$ dinucleotides, which are known to be relatively unstable for mutations (Vogel and Motulsky 1997), there may be many other missense mutations in Arg-565 in patients with MPS IIIB.

Tanaka et al. (2002) reported three MPS IIIB patients in two unrelated families from the Okinawa islands. Two siblings with an attenuated phenotype were compound heterozygous for R565P/F314L, and one patient with a severe phenotype was homozygous for R565P. To our knowledge, excluding Tanaka's report, 88 different mutations have been reported in 116 MPS IIIB patients, and 39 patients showed homozygous mutations (Zhao et al. 1998; Schmidtchen et al. 1998; Beesley et al. 1998; Bunge et al. 1999; Weber et al. 1999; Tessitore et al. 2000). In previous reports, no apparent common mutations were identified. Therefore, allelic heterogeneities of the NAGLU gene are assumed to contribute to the variability in the clinical phenotype of MPS IIIB patients. Including Tanaka's report (2002) eight MPS IIIB patients in seven families were not apparently related, which suggests that the prevalence of the R565P mutation in this small geographic area, the Okinawa islands, may be rather high, which further suggests a founder effect. The incidence of MPS III, including all four subtypes, has been estimated to be one in 24,000 live births in The Netherlands (van de Kamp et al. 1981), one in 66,000 in Australia (Meikle et al. 1999), and one in 280,000 in Northern Ireland (Nelson 1997). Although the number of our screened subjects was small, one person with an R565P heterozygous mutation was identified among 200 unrelated and unaffected subjects. Based on the Hardy-Weinberg law, the incidence of R565P homozygous MPS IIIB patients is estimated to be one in 160,000 in the Okinawa islands.

Acknowledgements We thank Dr. K. Hayasaka (Gifu University School of Medicine) for their contribution to the assay of NAGLU activities in fibroblasts.

\section{References}

Beesley CE, Young EP, Vellodi A, Winchester BG (1998) Identification of 12 novel mutations in the alpha- $N$-acetylglucosaminidase gene in 14 patients with Sanfilippo syndrome type B (mucopolysaccharidosis type IIIB). J Med Genet 35:910-914

Bunge S, Knigge A, Steglich C, Kleijer WJ, van Diggelen OP, Beck M, Gal A (1999) Mucopolysaccharidosis type IIIB (Sanfilippo B): identification of 18 novel alpha- $N$-acetylglucosaminidase gene mutations. J Med Genet 36:28-31

Hall CW, Liebaers I, Di Natale P, Neufeld EF (1978) Enzymic diagnosis of the genetic mucopolysaccharide storage disorders. Methods Enzymol 50:439-56

van de Kamp JJP, Niermeijer MF, von Figura K, Giesberts MAH (1981) Genetic heterogeneity and clinical variability in the Sanfilippo syndrome (types A, B, and C). Clin Genet 20:152160

Meikle PJ, Hopwood JJ, Clague AE, Carey WF (1999) Prevalence of lysosomal storage disorders. JAMA 281:249-254

Nelson J (1997) Incidence of the mucopolysaccharidoses in Northern Ireland. Hum Genet 101:355-358

Nelson DL, Cox MM (2000) Lehninger principles of biochemistry, 3rd edn. Worth, NY, pp 120-168

Schmidtchen A, Greenberg D, Zhao HG, Li HH, Huang Y, Tieu P, Zhao HZ, Cheng S, Zhao Z, Whitley CB, Di Natale P, Neufeld EF (1998) NAGLU mutations underlying Sanfilippo syndrome type B. Am J Hum Genet 62:64-69

Tanaka A, Kimura M, Lan HTN, Takaura N, Yamano T (2002) Molecular analysis of the ?-N-acetylglucosaminidase gene in seven Japanese patients from six unrelated families with mucopolysaccharidosis IIIB (Sanfilippo type B), including two novel mutations. J Hum Genet 47:484-487

Tessitore A, Villani GR, Di Domenico C, Filocamo M, Gatti R, Di Natale P (2000) Molecular defects in the alpha- $N$-acetylglucosaminidase gene in Italian Sanfilippo type B patients. Hum Genet 107:568-576

Vogel F, Motulsky AG (1997) Human genetics; problems and approaches, 3rd edn. Springer, Berlin Heidelberg New York, pp 413-415

Weber B, Blanch L, Clements PR, Scott HS, Hopwood JJ (1996) Cloning and expression of the gene involved in Sanfilippo B syndrome (mucopolysaccharidosis III B). Hum Mol Genet 5:771-777

Weber B, Guo XH, Kleijer WJ, van de Kamp JJ, Poorthuis BJ, Hopwood JJ (1999) Sanfilippo type B syndrome (mucopolysaccharidosis III B): allelic heterogeneity corresponds to the wide spectrum of clinical phenotypes. Eur J Hum Genet 7:34 44

Zhao HG, Li HH, Bach G, Schmidtchen A, Neufeld EF (1996) The molecular basis of Sanfilippo syndrome type B. Proc Natl Acad Sci USA 93:6101-6105

Zhao HG, Aronovich EL, Whitley CB (1998) Genotype-phenotype correspondence in Sanfilippo syndrome type B. Am J Hum Genet 62:53-63 